\title{
Iron coated peat as a sorbent for the simultaneous removal of arsenic and metals from contaminated water
}

\author{
A. Kasiuliene ${ }^{1}$, I. Carabante ${ }^{1}$, J. Kumpiene ${ }^{1} \&$ P. Bhattacharya ${ }^{2}$ \\ ${ }^{1}$ Waste Science and Technology Research Group, Department of Civil, \\ Environmental and Natural Resources Engineering, Lulea University of Technology, Lulea, Sweden \\ ${ }^{2}$ KTH-International Groundwater Arsenic Research Group, Department of Sustainable Development, \\ Environmental Science and Engineering, KTH Royal Institute of Technology, Teknikringen, Stockholm, Sweden
}

\begin{abstract}
This study aimed at combining peat, an industrial residue, with $\mathrm{Fe}(\mathrm{II})-\mathrm{Fe}(\mathrm{III})$ compound to produce a sorbent suitable for a simultaneous removal of arsenic (As) and metals (cadmium, copper, nickel, lead, zinc) from a contaminated water. Using a newly produced sorbent - iron-peat - the removal of As from contaminated water was almost 17 times higher than using an uncoated peat. On the other hand, the removal of metals by the iron-peat was slightly less efficient in comparison to the uncoated peat. Simultaneous removal of As and metals could be seen as an advantage over multiple-step treatment of contaminated groundwater.
\end{abstract}

\section{INTRODUCTION}

In Sweden, due to the legacies of past industrial activities, such as glass works and wood impregnation, multiple point sources of arsenic (As) contamination in soil and water bodies are scattered over the country. In several of these sites, other metals, such as cadmium $(\mathrm{Cd})$, copper $(\mathrm{Cu})$, nickel $(\mathrm{Ni})$, lead $(\mathrm{Pb})$ or zinc $(\mathrm{Zn})$ occur as co-contaminants at varying concentrations depending on the type of industrial activities.

A common method to remove As from contaminated water is by adsorbing them onto reactive media and separating from solution. Iron $(\mathrm{Fe})$ oxides have an affinity for arsenates and are used as an effective and potentially inexpensive adsorbent to treat As contaminated water (Carabante, et al., 2014). To avoid clogging of filters (Mohan \& Pittman, 2007) and overcome low hydraulic permeability (Theis et al., 1992), Fe-containing filters commonly are produced by coating a bulk material, e.g. sand (Devi et al., 2014) or activated carbon (Yürüm et al., 2014) with Fe oxides. Activated carbon has an advantage over sand, because it can target contaminants as well. Replacing activated carbon with cheaper and readily available materials, e.g. peat could lead to a production of a more costefficient sorbent. Furthermore, peat by itself can target divalent metal ions.

The aim of this study was to develop a residue-based sorbent for the simultaneous removal of $\mathrm{As}, \mathrm{Cd}, \mathrm{Cu}$, $\mathrm{Ni}, \mathrm{Pb}$, and $\mathrm{Zn}$ from contaminated groundwater, which after the use could be combusted for energy recovery and mass reduction.

\section{MATERIALS AND METHODS}

\subsection{Materials}

Heat-treated peat powder was obtained from Geogen Produktion AB, Sweden. This company produces heattreated peat granulate as environmentally compatible oil-absorption agent. During its production, powder particles smaller than $2 \mathrm{~mm}$ are discarded and considered as a waste.

Ferriferous hydrosol (FFH) was used for coating the peat. The hydrosol is a product of $\mathrm{Fe}$ (II) and $\mathrm{Fe}(\mathrm{III})$ hydrated compounds. FFH is a commercially available product produced from the $\mathrm{Fe}$ waste; it was obtained from Rekin, Lithuania.

Solution containing As and metals used for adsorption test was prepared from chemicals of analytical grade provided by Fluka or Merck: $\mathrm{NaH}_{2} \mathrm{AsO}_{4}, \mathrm{CdCl}_{2}$, $\mathrm{CuCl}_{2} * 2 \mathrm{H}_{2} \mathrm{O}, \mathrm{NiCl}_{2}, \mathrm{~Pb}\left(\mathrm{NO}_{3}\right)_{2}$, and $\mathrm{ZnCl}_{2}$. Concentrations of As and metals in the initial solution before adsorption experiment were detected with ICP-OES (Perkin Elmer Optima 2000V). Solution's pH was set to 5.0 using $\mathrm{NaOH}$ solutions.

\subsection{Methods}

Batches of iron-peat sorbent were prepared mixing FFH and peat powder at three different ratios: 1:1, $1: 10$, and $1: 20$, respectively. Each sorbent (in triplicate) was mixed with the prepared As and metal solution at a liquid to solid ratio $(\mathrm{L} / \mathrm{S})=1000$. Uncoated peat was used as reference. Mixtures were shaken for $24 \mathrm{~h}$, then samples were filtered through $0.45 \mu \mathrm{m}$ 


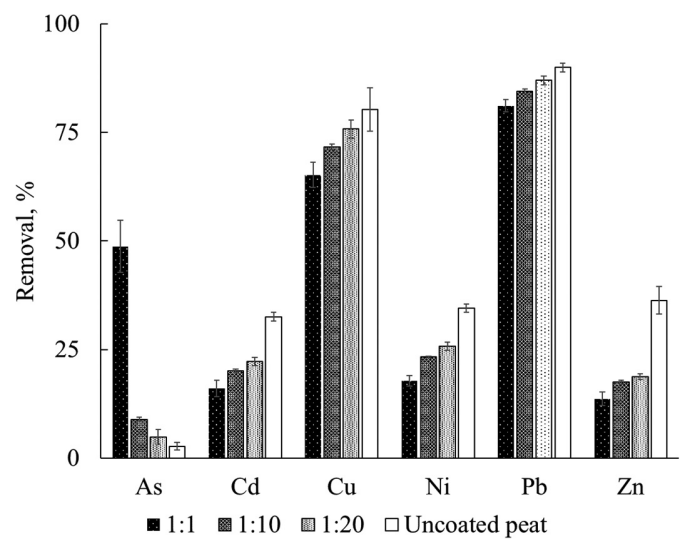

Figure 1. Removal of As and metals from contaminated solution using iron-peat at three different ratios and uncoated peat as a reference.

nitrocellulose filters and leachates were analyzed with ICP-OES.

The data were processed by analysis of variance (ANOVA) using the software Minitab 18. A twosample t-test $(\mathrm{p}<0.05)$ was applied to differentiate between sample means.

\section{RESULTS AND DISCUSSION}

\subsection{Arsenic removal efficiency}

Concentration of As in the initial solution was $0.54 \mathrm{mg} \mathrm{L}^{-1}$. Iron-peat, where FFH was coated onto peat at a 1:1 ratio, was the most effective to adsorb As from contaminated water. The removal efficiency was about $50 \%$ (Fig. 1). Other treatments (1:10, 1:20, uncoated peat) were significantly weaker and the removal of As remained below $10 \%$. Obtained results well coincide with other studies (e.g. Kumpiene et al., 2009; Vitkova et al., 2017) where high affinity of arsenate to be adsorbed on Fe oxides has been reported.

\subsection{Metal removal efficiency}

Metal concentrations in the initial solution were: $0.80 \mathrm{mg} \mathrm{L}^{-1}$ of Cd, $4.3 \mathrm{mg} \mathrm{L}^{-1}$ of $\mathrm{Cu}, 0.80 \mathrm{mg} \mathrm{L}^{-1}$ of $\mathrm{Ni}, 2.2 \mathrm{mg} \mathrm{L}^{-1}$ of $\mathrm{Pb}$, and $4.0 \mathrm{mg} \mathrm{L}^{-1}$ of $\mathrm{Zn}$. Contrary to the removal of As, all investigated metals were better adsorbed onto uncoated peat. A clear metal removal efficiency pattern of the four sorbents can be observed from Figure 1. The results indicate that peat can efficiently bind to divalent metal ions due to its polar characteristics. It can be assumed that $\mathrm{Fe}$ compounds, occurring due to the coating, were blocking organic groups in the peat. Therefore, the removal rate of metals using coated peat was weaker in comparison to the adsorption by uncoated peat.

\subsection{Overall performance of the iron-peat}

Simultaneous sorption of As and metals from contaminated aqueous media was achieved using a newl produced iron-peat sorbent. Process optimization for specific groundwater conditions could further increase the sorption capacity of the sorbent. Adjustment of $\mathrm{pH}$ and reduction of contaminated water loads could substantially enhance the removal efficiency. Iron-peat sorbent could be used in filters, packed-bed reactors, or in passive permeable barriers to treat contaminated water. Number of treatment steps could be reduced due to the sorbent's ability simultaneously adsorb As and metals.

Results obtained from this study has not only environmental impact on cleaning contaminated water, but also emphasizes utilization of by-products, which also contribute to the volume reduction of waste materials to be treated.

\section{CONCLUSIONS}

Iron coating on peat $(1: 1)$ significantly increased As removal from contaminated water in comparison to other treatments. Metal removal was slightly higher onto uncoated peat in comparison to iron-peat. The results indicate that iron-peat simultaneously targets both As and divalent metals and could be used as a single-step treatment for contaminated water.

\section{ACKNOWLEDGEMENTS}

The authors would like to thanks the Swedish Research Council for Sustainable Development (Formas) for the research grant for this study.

\section{REFERENCES}

Carabante, I., Mouzon, J., Kumpiene, J., Gran, M., Fredriksson, A. \& Hedlund, J. 2014. Reutilization of porous sintered hematite bodies as effective adsorbents for arsenic(V) removal from water. Ind. Eng. Chem. Res. 53(32): 12689-12696.

Devi, R.R., Umlong, I.R., Das, B., Borah, K., Thakur, A.J., Raul, P.K., Banerjee, S. \& Singh, L. 2014. Removal of iron and arsenic(III) from drinking water using iron oxide-coated sand and limestone. Appl. Water Sci. 4(2): $175-182$.

Kumpiene, J., Ragnvaldsson, D., Lovgren, L., Tesfalidet, S., Gustavsson, B., Lattstrom, A., Leffler, P. \& Maurice, C. 2009. Impact of water saturation level on arsenic and metal mobility in the Fe-amended soil. Chemosphere 74(2): 206-215.

Mohan D. \& Pittman, C.U. 2007. Arsenic removal from water/wastewater using adsorbents - a critical review. J. Hazard. Mater. 142(1-2): 1-53.

Theis, T.L., Iyer, R. \& Ellis, S.K. 1992. Evaluating a new granular iron oxide for removing lead from drinking water. J. Am. Water Works Assoc. 84(7): 101-105.

Vitkova, M., Rakosova, S., Michalkova, Z. \& Komarek, M. 2017. Metal(oid)s behaviour in soils amended with nano zero-valent iron as a function of $\mathrm{pH}$ and time. J. Environ. Manage. 186: 268-276.

Yürüm, A., Kocabaş-Ataklı, Z.Ö., Sezen, M., Semiat, R. \& Yürüm, Y. 2014. Fast deposition of porous iron oxide on activated carbon by microwave heating and arsenic (V) removal from water. Chem. Eng. J. 15: 321-332. 